\title{
Insulin Aggregation in Artificial Delivery Systems
}

\author{
W. D. Lougheed ${ }^{1}$, H. Woulfe-Flanagan ${ }^{2}$, J. R. Clement ${ }^{2}$, and A. M. Albisser ${ }^{1}$ \\ ${ }^{1}$ The Hospital for Sick Children and \\ ${ }^{2}$ Connaught Laboratories Limited, Toronto, Canada
}

Miniature "open-loop" devices have been used successfully to deliver insulin intravenously and maintain normoglycaemia for periods of up to $2^{1 / 2}$ years in diabetic dogs $[1,2]$. However, a tendency of insulin to aggregate at both 25 and $37^{\circ} \mathrm{C}$ has led to serious problems in delivery and has necessitated frequent replacement or flushing of the insulin reservoircatheter system. The heterogeneous mixture produced by insulin aggregation in portable and implantable delivery systems does not allow delivery of the hormone within the fine limits of tolerance that are required to maintain euglycaemia. The premature end of attempted extended infusion is thus often caused by the obstruction of internal pump parts and/ or the delivery catheters [3]. Insulin has an inherent tendency to polymerize [4] and form large molecular weight aggregates [5] that do not equilibrate rapidly with the rest of the solution. Insulin aggregation in artificial devices is thus the major impediment to their further technological development and clinical application. With subcutaneous infusion devices [6, 7], these problems have not been reported, possibly due to the frequent changing of the insulin containing portion of the devices. Only upon the complete resolution of the aggregation problem can the new intravenous therapeutic methods be properly assessed as to their effect on the aetiology of diabetic complications.

This paper reviews the relevant published literature and attempts to consolidate the physical, chemical and thermodynamic factors that lead to insulin aggregation. Such knowledge may expedite the development of insulin formulations and the selection of materials suitable for the uncomplicated longterm administration of the hormone.

\section{Relevant Literature}

The aggregational behaviour of pork and beef insulins in both acid and neutral formulations has been discussed [4, 5, 8-21]. In this paper, unless otherwise stated, it will be assumed that 'insulin' refers to these four insulin formulations only. The terms self-association, polymerization and aggregation have been used interchangeably in the literature. We assume that all authors in fact refer to the same phenomenon but in the sections relevant to our work we shall use the term "aggregates" to describe those particles (visible at $400 \mathrm{X}$ magnification) which have been responsible for the occlusion of our insulin infusion devices.

The stoichiometry of the self-association or aggregation of insulin was described by Steiner as early as 1952 [20]. These early studies at $\mathrm{pH}$ 2.06-3.07 (19-40 $\left.{ }^{\circ} \mathrm{C}\right)$ proposed a model which involved dimers, tetramers and hexamers in reversible equilibrium. Since then, many models have been proposed to describe the self-association of insulin in solution at both acid and neutral $\mathrm{pH}$. The early studies used sedimentation velocity measurements to determine the species in suspension. More recent work has included sedimentation equilibrium and circular dichroism techniques. Most early models were qualitatively similar to each other involving monomer-dimer-hexamer-polymer formation $[9,11,21]$ although disagreement existed regarding the size of the monomer [11]. Grant et al. [13] reported that the hexamer was the sole component present at zinc concentrations higher than two g-atoms/hexamer $(\mathrm{pH}$ 7.0). Models which incorporated the finite existence of the tetramer were also proposed but work with zinc-free insulin at neutral $\mathrm{pH}$ seemed to indicate monomer-dimer association followed by dimer-hexamer association.

In 1977, Holladay et al. [22] reported association constants for these reactions $\left(\mathrm{K}_{2}=2.2 \times 10^{4} 1 / \mathrm{mol}\right.$, $\mathrm{K}_{6}=8.6 \times 10^{9} \mathrm{I}^{2} / \mathrm{mol}^{2}$ ) which were in fairly close agreement with those reported earlier by Pekar and Frank $[18]\left(\mathrm{K}_{2}=1.4 \times 10^{5} \mathrm{l} / \mathrm{mol}, \mathrm{K}_{6}=4 \times 10^{8} \mathrm{l}^{2} /\right.$ $\mathrm{mol}^{2}$ ). In 1976 Jeffrey et al. [4] using a broader range of zinc-free insulin concentrations fitted their results to a model in which monomer-dimer association $\left(\mathrm{K}_{2}\right.$ 
$=1.1 \times 10^{5} \mathrm{l} / \mathrm{mol}$ ) was followed by indefinite selfassociation of the dimer to form higher polymers ( $\mathrm{K}$ $=1.7 \times 10^{4} \mathrm{l} / \mathrm{mol}$ ). Blundell et al. [8] and Thurow [23] agreed with Jeffrey that the dimer was the fundamental unit for further association. Blundell et al. proposed that dimer formation involved relatively weak intermolecular Van der Waal's forces as well as hydrogen bonding in the monomer interface region (pleated sheet region) which is common to both insulin and proinsulin. Recently, Jeffrey [5], employing similar sedimentation equilibrium techniques $(\mathrm{pH} 2$ and 7) reported: (1) that zinc insulin species of higher molecular weight than the hexamer were present and could exist in solution for sufficient time to conduct equilibrium sedimentation experiments; (2) that these aggregates were not in rapid equilibrium with the monomer-dimer-hexamer system; (3) that as reported by others $[11,18]$ the aggregation process was concentration-dependent with disassociation to the monomer occurring at very low concentrations and the formation of dimers, tetramers, hexamers and higher polymers proceeding as the insulin concentration was progressively raised; (4) that the aggregation behaviour of zinc-free insulin ( $\mathrm{pH} 7.0$ ) as reported by Pekar and Frank [18] was qualitatively similar to that of zinc insulin ( $\mathrm{pH} 7.0)$; (5) that glucose $(7.76 \mathrm{~g} / 100 \mathrm{ml})$ favoured dissociation at both $\mathrm{pH} 2$ and $\mathrm{pH} 7$ but that large molecular weight aggregates still made a significant contribution to the sedimentation coefficient at $\mathrm{pH} 7$. Some of the cited authors, notably Jeffrey [5], have reported variable aggregation behaviour in samples from the same lot and attribute this to the retention of varying amounts of large molecular weight aggregates in solution.

Wu [24] has criticized Pekar and Frank [18] and Jeffrey [5] in that they failed to consider the effect of storage time on aggregation behaviour in solution. Thus, it must be noted that the quoted experiments were conducted with protocols that would not detect any relationship between stability and increased aggregation. In sedimentation velocity experiments Wu [24] has also noted that insulins from the same batch showed an inconsistent propensity for aggregation. In addition he reported that on at least two occasions when a solution of $125 \mathrm{U}$ highly purified insulin $/ \mathrm{ml}$ at $\mathrm{pH} 7$ (in $0.1 \mathrm{~mol} / 1$ Tris buffer, $0.1 \mathrm{~mol} / 1$ $\mathrm{NaCl}, 0.001 \mathrm{~mol} / \mathrm{l}$, EDTA) was refrigerated for a period of a few days a precipitate formed in the glass vials. The precipitate did not redissolve in fresh diluent. The author added that the large molecular weight aggregates may be 'other forms' of "denatured" insulin molecules present in the stock solution.

Contrary to the above reports describing insulin aggregation by simple thermodynamic equilibria it has been proposed that the aggregation of insulin is a complex phenomenon. In support of this the literature abounds with articles that cite the following as variables which influence aggregation behaviour: insulin purity, nature and concentration of metal ions, processing methods, refrigeration temperatures, elevated temperatures (above $31^{\circ} \mathrm{C}$ ), ionic strength, elevated salt concentrations during processing, motion and denaturation. In the remainder of this review we shall summarize some of these variables which reportedly contribute to the process of insulin aggregation.

\section{Purity}

Jackson et al. [25] suggested that the purity of insulin solutions at neutral $\mathrm{pH}$ was a prerequisite for solubility. In addition, other authors have proposed that impurities (such as proinsulin) may have been responsible for or enhanced aggregation [5, 24]. Regular (soluble) insulin preparations usually contain varying low levels of contaminants $[25,26]$ e. g.: desamido insulin, ethyl esters of insulin, proinsulin and other partially processed forms of the hormone [27]. From 1972-1975 advances in purification technology considerably reduced the level of these contaminants in special preparations. "Single Component" (SC) insulin (Eli Lilly) and "Monocomponent" (MC) insulin (Novo) which were purified by both molecular sieve and ion exchange chromatography contained $99 \%$ pure insulin and less than $1 \mathrm{ppm}$ of such contaminants as proinsulin or glucagon [29]. Unfortunately the insulin molecule is not a stable entity. Although biological potency is not substantially reduced under the appropriate storage conditions (losses of less than $1 \%$ during shelf life at $2-8^{\circ} \mathrm{C}$ ), insulin transformation products are formed [29]. The products are mainly desamido insulins and insulin polymers, primarily dimers.

The claims of purity for MC insulin have been challenged by some investigators. Yue and Turtle [30] from their chromatographic analysis claimed that $5 \%$ of the protein in MC insulin was covalently linked dimer and that its proinsulin content was $0.049 \%$. Schlichtkrull [31] refuted the analysis of the above authors attributing their results to the presence of preservative in their insulin samples.

In view of these controversial data one cannot draw any definitive conclusions except that all insulin solutions regardless of purity demonstrate a propensity towards aggregation. Until a truly homogeneous solution of insulin is obtained the precise relationship between purity and aggregation cannot be determined. 


\section{Metal Ions}

It has been reported that excess amounts of divalent metal ions, notably $\mathrm{Zn}^{2+}, \mathrm{Cu}^{2+}, \mathrm{Fe}^{2+}$, will cause insulin at neutral $\mathrm{pH}$ 's to form large molecular weight aggregates (mol. wt. $=10^{5}$ to $2 \times 10^{5}$ ) $[9,32]$. This seems reasonable as the addition of $\mathrm{Zn}$ under appropriate conditions results in crystallization of the hormone. However, Wu [24], reported that aggregation occurred during experimentation with zinc-free insulin in the presence of a chelating agent such as EDTA. It was, however, the above author's contention that the removal of zinc was necessary to reduce the tendency towards self-association. In addition, Massey and Smyth [33] reported that zinc-free insulin revealed aggregates during gel filtration but to a lesser extent than zinc insulin. Sulphated insulin which is zinc-free tends to exist as a monomer [34], but this may be due to additional charges on the molecule introduced by the sulphate groups.

\section{Temperature}

The stability of insulin solutions at temperatures between -20 and $+37^{\circ} \mathrm{C}$ is well documented [35]. One notable study [36] has defined stability as $\mathrm{P}(\mathrm{t})=$ $\mathrm{P}_{\mathrm{o}} \mathrm{e}^{-\mathrm{kt}}$ where $\mathrm{t}=$ time, $\mathrm{P}_{\mathrm{o}}=$ biological activity at $\mathrm{t}=$ 0 , and $\mathrm{k}=\mathrm{e}^{\mathrm{BT}}$, where $\mathrm{T}=$ absolute temperature and $\mathrm{B}$ is a proportionality constant. Instability of insulin solutions at 25 and $37^{\circ} \mathrm{C}$ has been noted $[19,23]$. Whether denaturation of the hormone at elevated temperatures caused aggregation of the hormone is not clear from the literature. It has been observed that the decline with time in immunological activity is less than the decline in biological activity [35] which might perhaps be explained on the basis of aggregation or partial denaturation.

\section{Processing}

The presence of high molecular weight aggregates in freshly prepared insulin solutions stored at $4{ }^{\circ} \mathrm{C}$ has been reported [27]. At the time the above authors reported that the chemical nature of these cross-linkages had not been elucidated but evidently these aggregates were formed during the extraction and isolation of insulin under acid conditions and were present at low levels in all solutions unless further methods for their removal were implemented [26, 28 ]. With respect to salting out of the hormone during processing it has been postulated that hypertonic salt concentrations may alter the conformation of the crystalline protein [19].

\section{Motion}

The effect of movement upon the hormone is not well documented. Irsigler and Kritz [3] reported that the precipitation of insulin in infusion devices appeared to be an unavoidable consequence of continuous motion of the hormone and that aggregation or precipitation occurred irrespective of the materials used in the pumping system. Thurow [23, 38] reported that factors which accelerated denaturation also increased aggregation and he cited agitation as an important variable.

\section{Other Variables}

Among other variables noted in the literature are: (1) that high ionic strength favours association [19]; (2) that association or aggregation affects only the average mobility of the protein with conformation remaining unchanged [19]; (3) that the usual low storage temperature of $4^{\circ} \mathrm{C}$ favours association [24].

Purity, homogeneity, temperature, metal ions, processing methods, ionic strength, and motion are all variables implicated in the aggregation of insulin. The relative importance of the above variables has not yet been established. Presented below are the results of our own investigations.

\section{Biomaterials and Construction}

One of the more disputed points is whether insulin adsorption to the pump and/or catheter surfaces is fundamental to the insulin plugging problem. Although several experiments conducted over the last year do not entirely answer this question they do provide definite insights into the behaviour of insulin and its compatability with delivery systems.

Insulin solutions appear to polymerize preferentially in solution rather than forming complex coatings on the surfaces of pumping systems. Polymerization may, however, be a surface process and thus influenced by materials employed within the system. The materials tested included polytetrafluoroethylene (PTFE), titanium, silicone rubber, glass, polyvinylchloride (PVC) and cellulose acetate in the form of 0.22 micron pore filters.

Two implanted pumps (Infusaid (is), Metal Bellows Corp., Sharon, Mass.) were explanted after 6 to 9 weeks of intravenous insulin delivery. The pumps were disassembled and all parts concerned were viewed with scanning electron microscopy (SEM) to determine the extent of insulin aggregation on the surfaces. Both pumps were found to be occluded 
within the fine $61 \mu \mathrm{m}$ diameter PTFE flow restricting capillary $1-2 \mathrm{~cm}$ down stream from the pump. The plugs, analysed by Eli Lilly and Co., contained substantial amounts of immunoreactive insulin. However all other sections of the teflon capillary were free of deposition (SEM at $1000 \mathrm{X}$ ) with no difference between these and control sections. It is noteworthy to add that the capillaries in the pump were approximately $2.7-3.0 \mathrm{~m}$ in length and that if adhesion to the teflon surface were indeed a significant precipitating factor then at least some form of distributed deposition should have been visualized. The cellulose acetate filter discs also showed little or no deposition as compared to controls. Any tendency towards aggregation on the surface of this material would be expected to occlude the 0.22 micron pores. The titanium surfaces of the pump reservoir were discoloured but this was found to be copper deposition due to a welding procedure employed during manufacture.

The two silastic catheters leading from the plugged pumps were also cut transversely into $1 \mathrm{~cm}$ lengths and viewed with light and scanning electron microscopy. Both catheters contained white aggregates of insulin along their entire length. The viscous white aggregates within the sections dissolved after standing for 5-10 min at room temperature and the catheter sections all became patent. This phenomenon will be discussed in a later section under the heading of $\mathrm{CO}_{2}$ diffusion and $\mathrm{pH}$. The sections of silastic catheter were rinsed lightly in distilled water and viewed (SEM at $1000 \mathrm{X}$ magnification) with no significant difference being noted between the above surfaces and control sections.

Further experiments to determine the effect of luminal restrictions on insulin plug formation were conducted. To this end ten $20 \mathrm{~cm}$ long PTFE capillaries were cut at both ends using a method [39] that ensures an undistorted entrance or exit to flow. In addition, 10 similar control capillaries were cut as above at the upstream end only. The downstream ends however were cut with a sharp razor blade. This method caused distortion and barbing of the lumen. Regular pork insulin $(10 \mathrm{U} / \mathrm{ml}, \mathrm{pH} 7.5)$ was pumped from a 11 glass vessel (at $25^{\circ} \mathrm{C}$ ) through the capillaries (at $37{ }^{\circ} \mathrm{C}$ ) and into sterile glass vials. No decrease in flow rate was observed in 9 out of 10 well cut capillaries after 90 days. The one occluded capillary was sectioned for microscopic examination and the occlusion was found to be particulate matter. Flow in all of the poorly cut PTFE tubes ceased within 20 days. The plugs in these were analyzed by Eli Lilly and Co. and viewed under the SEM. Formed aggregates were partially amorphous and partially crystalline insulin. All of the above plugs were located at the down stream poorly cut exit with insulin aggregates being clearly held within the PTFE barbs protruding into the exit region of the capillaries.

In addition, experience over the last year with our portable insulin delivery systems [1] has revealed that the majority of occlusions occur or collect at tubing junctions where the lumen narrows. The insulin reservoirs (Silicone rubber, PVC and titanium) for both the implantable and portable systems have been inspected regularly and insulin aggregates have been found in all reservoirs that had not been flushed or changed every $3-4$ days.

We conclude that flow path restrictions and/or irregularities are contributing variables in the plugging of insulin delivery systems, and that the selfassociating behaviour of insulin formulations most probably allows aggregates generated upstream to accumulate in these regions. The degree to which surface interactions, temperature and motion affect the above phenomena has only been partially addressed but will be discussed in a subsequent section.

\section{Metal Ions and Aggregation}

As stated previously it has been suggested that the removal of zinc and other metal ions from insulin solutions may decrease self-association. To address this problem three vials $(5 \mathrm{U}$ insulin $/ \mathrm{ml}, 0.154 \mathrm{~mol} / 1$ $\mathrm{NaCl}, \mathrm{pH} 7.5$ ) containing clean etched copper and controls without copper were subjected to gentle rocking at $38{ }^{\circ} \mathrm{C}$. Visible precipitation occurred in those vials containing copper within $4 \mathrm{~h}$. Visible aggregation appeared in the controls only after 3-4 days.

Two occlusions within the teflon capillaries of the implanted pumps were attributed to the above mechanism. Unlike the white insulin precipitates that we have repeatedly found in our insulin delivery systems, these plugs were a transluscent brown. Analysis using atomic absorption techniques showed the plugs to contain $1.6 \times 10^{4} \mathrm{ppm} \mathrm{Cu}$ and $2.3 \times 10^{4} \mathrm{ppm} \mathrm{Zn}$ while the reservoir solution contained only $1.4 \mathrm{ppm}$ $\mathrm{Cu}, 2.0 \mathrm{ppm} \mathrm{Zn}$. Subsequent radioimmunoassay substantiated the presence of insulin. The divalent copper ions were evidently highly concentrated within the plug material. Investigation revealed that copper contamination had occurred during manufacturing and that electrolysis (emf of 0.14 volts between solution and reservoir) was responsible for driving the copper into solution. Implantable pumps (Infusaid (ix) employing a titanium insulin reservoir and a stainless steel capillary produced similar occlusions which contained substantial amounts of Fe. The same electrolytic process can be attributed to these plug formations.

The presence of certain metal ions is without question a contributing factor in insulin aggregation. 
With the employment of more insulin-compatable metallic pump parts (ie. titanium) in combination with zinc-free insulin formations the catalysing effect of metal ions upon aggregation can be eliminated.

\section{Thermodynamic Factors}

To test the thermodynamic effects of temperature, motion and certain diluents an in vitro experiment was performed in which neutral pork insulin $(5 \mathrm{U} /$ $\mathrm{ml}$ ) contained in $50 \mathrm{ml}$ capacity sterile glass vials was gently rocked (Pharmacia Roto-Tak Rotor) at 37 and $25^{\circ} \mathrm{C}$ for 30 days. Control vials for each of the solutions tested were placed at 37 and $25{ }^{\circ} \mathrm{C}$ but not subjected to movement. The solutions were tested in triplicate.

The results of the experiment are presented in Table 1. Noteworthy conclusions are: (1) After 30 days only small amounts of aggregates were observed in those vials that were stationary and at $25^{\circ} \mathrm{C}$. (2) All vials at $37^{\circ} \mathrm{C}$ (no motion) demonstrated moderate to severe aggregation (granular particles). Birefringence indicated that these aggregates were partially crystalline. One exception to the above was sulphated insulin. Only minor aggregation was witnessed under $400 \mathrm{X}$ mag. (3) All vials subjected to gentle rocking contained moderate to extremely severe granular and strand-like formations excepting the sulphated insulin which demonstrated only a minor tendency towards aggregation. The strand-like or fibrous formations were observed only in those vials subjected to continuous motion. (4) The combination of elevated temperature $\left(37^{\circ}\right)$ and gentle motion resulted in a higher degree of aggregation than was observed in those vials subjected only to elevated temperature or continuous motion alone. (5) Those solutions containing $0.154 \mathrm{~mol} / 1$ saline demonstrated the most severe propensity towards aggregation. (6) Extremely small quantities of microscopic granular like aggregates were present in 3 of the 12 vials of regular pork insulin $(100 \mathrm{U} / \mathrm{ml})$ before the initiation of the experiment. These aggregates varied from $2.5-25 \mu \mathrm{m}$ in diameter. Samples from a random selection of vials from a number of manufacturers also showed varying but minute quantities of crystalline and amorphous aggregates. The small quantities would have negligible impact on normal usage of the formulation but may well promote occlusion under the specific conditions encountered during slow pumping through narrow extended capillaries. During this experiment no attempt was made to maintain $\mathrm{pH}$ levels by the addition of buffers. However, in all cases the $\mathrm{pH}$ remained between 6.65 and 7.5 over the 30 day period.

As stated, the instability of insulin solutions at room temperature has been noted and the propensity for insulin to precipitate when in continuous motion has also been acknowledged by Irsigler and Kritz [3] and Thurow [23].

The successful delivery of insulin described earlier through well cut PTFE capillaries is undoubtedly due to the fact that the insulin delivery vial was maintained at $25^{\circ} \mathrm{C}$ and was kept stationary. Thus aggregates large enough to occlude the lumen were not formed.

A further observation on the effect of motion was made during an experiment in which two vials of Insulin Toronto (Connaught Laboratories Ltd.) were checked for signs of gross aggregation. One vial (100 $\mathrm{U} / \mathrm{ml}$ ) was shaken rapidly (low speed - Eberbach Reciprocal Shaker) and became opaque with precipitate after less than 4 days of this motion. A second vial which has been rocked gently (Pharmacia RotoTak Rotor) for over 4 months does not yet contain precipitates detectable by eye. Both experiments were carried out at $38^{\circ} \mathrm{C}$.

Experiments were also carried out to test the effect of vigorous shaking $\left(38^{\circ} \mathrm{C}\right)$ in glass containers. Connaught Neutral Pork, specially purified pork insulin and Actrapid (Novo MC Pork) in 3-5 replicates and at a concentration of $5 \mathrm{U} / \mathrm{ml}$ were used in neutral $0.154 \mathrm{~mol} / 1 \mathrm{NaCl}$ solutions ( $\mathrm{pH} 7.3-\mathrm{pH} 7.5$ ). The formulations were examined by the unaided eye and by light microscopy for signs of aggregation. Gross aggregation occurred in all vials within 3-8 days.

Increased purification of the insulin may enhance the stability of the formulations, but in the above experiments increased purification of insulin did not delay the onset of aggregation.

Many other solutions were screened in the preliminary experiments described above and the results, listed in Table 2, show the time at which solutions demonstrated severe aggregation.

The preliminary results reported above indicate that although some additives, namely benzyl alcohol and SDS, do stabilize the formulations to a limited extent, further experiments are required to produce insulin solutions suitable for protracted infusion. New formulations are currently being tested as above and also by a method developed by Thurow [23], described below.

Thurow used a wheel on which vials were rotated at $60 \mathrm{rpm}$ at a distance of $20 \mathrm{~cm}$ from the axis in order to test the stability of insulin solutions. The effect of additives on solutions of zinc-free bovine insulin $400 \mathrm{U} / \mathrm{ml}$ in Tris- $\mathrm{HCl}(0.05 \mathrm{~mol} / 1 ; \mathrm{pH} 7.5)$ and containing $1.8 \mathrm{~g} / 100 \mathrm{ml}$ glycerol was studied. The times, reported by Thurow at Aachen, in which denaturation of insulin to form a turbid gel occurred, are listed in Table 3. The experiments were conducted at $37^{\circ} \mathrm{C}$. 
Table 1

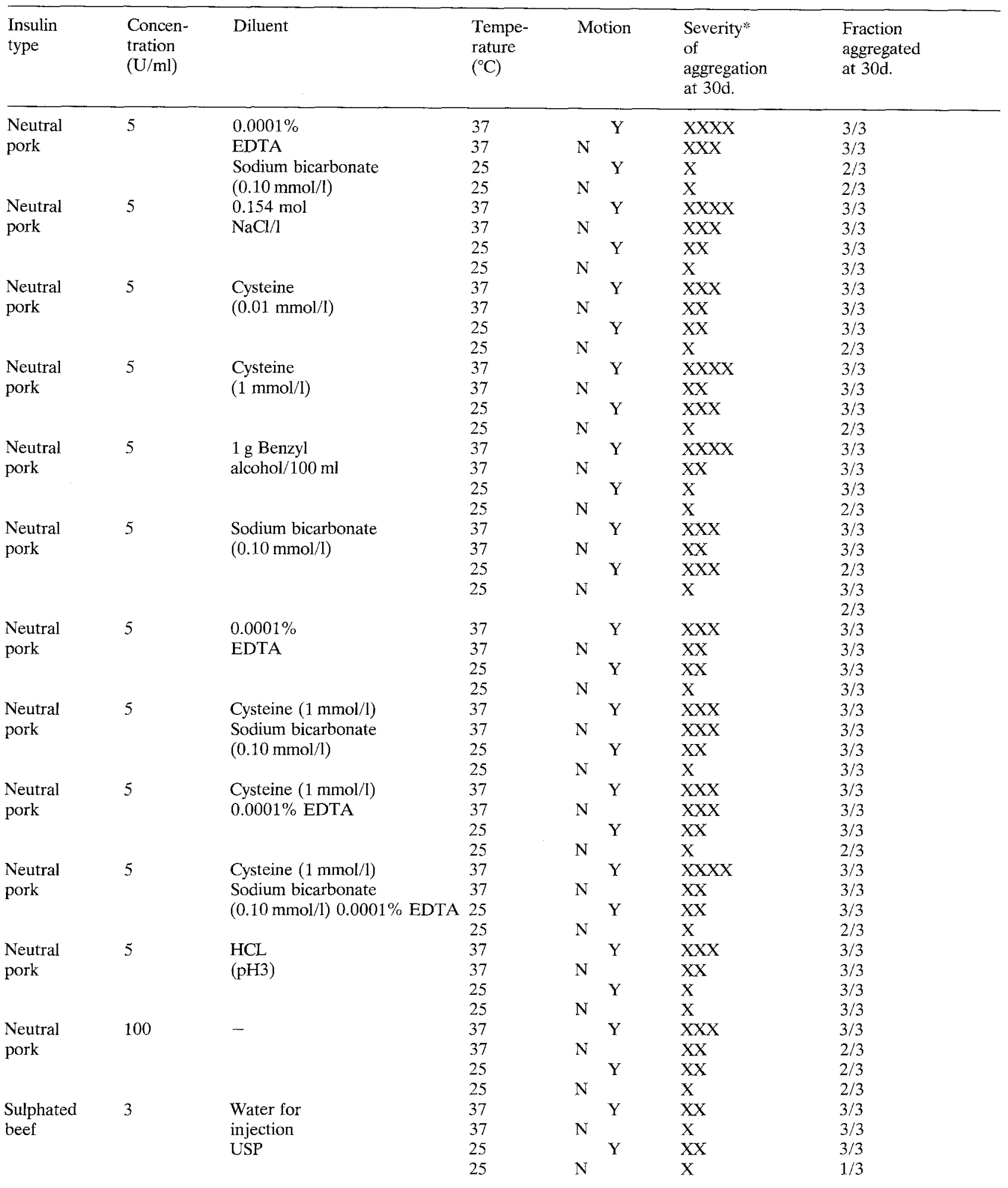

$X=10,2-5 \mu \mathrm{m}$ aggregates $/ 50 \mu \mathrm{l}$

$\mathrm{XX}=10-20,10 \mu \mathrm{m}$ aggregates $/ 50 \mu \mathrm{l}$

$\mathrm{XXX}=20-100,10 \mu \mathrm{m}$ or $>$ aggregates $/ 50 \mu \mathrm{l}$

$\mathrm{XXXX}=100,10 \mu \mathrm{m}$ or $>$ aggregates $/ 50 \mu \mathrm{l}$

$\mathrm{Y}$ indicates solution in motion

$\mathrm{N}$ indicates no motion

* All observations made at $400 \mathrm{X}$ magnificiation 
Table 2

\begin{tabular}{|c|c|c|c|}
\hline $\begin{array}{l}\text { Insulin } \\
(5 \mathrm{U} / \mathrm{ml})^{b}\end{array}$ & Diluent & Container & $\begin{array}{l}\text { Time to visible } \\
\text { aggregation (days) }\end{array}$ \\
\hline Sulphated beef & $\mathrm{NaCl}(0.154 \mathrm{~mol} / \mathrm{l}) \mathrm{pH} 6.4$ & Glass \& PVC & $13-60^{\mathrm{a}}$ \\
\hline Sulphated beef & $\mathrm{NaCl}(0.154 \mathrm{~mol} / \mathrm{l}) \mathrm{pH} 7.4$ & Glass \& PVC & $13-60^{a}$ \\
\hline Neutral pork & $\mathrm{NaCl}(0.154 \mathrm{~mol} / \mathrm{l})$ with $0.005 \%$ SDS & Glass \& PVC & $4-7$ \\
\hline Neutral pork & $\mathrm{NaCl}(0.154 \mathrm{~mol} / \mathrm{l})$ with $0.05 \%$ SDS & Glass & $35^{\mathrm{a}}$ \\
\hline Sulphated beef & benzyl alcohol $1.0 \mathrm{~g} / 100 \mathrm{ml} \mathrm{pH} 6.4$ & Glass \& PVC & $13-60^{\mathrm{a}}$ \\
\hline Sulphated beef & benzyl alcohol $1.0 \mathrm{~g} / 100 \mathrm{ml} \mathrm{pH} 7.4$ & Glass \& PVC & $13-60^{\mathrm{a}}$ \\
\hline Neutral pork & $\mathrm{NaCl}(0.154 \mathrm{~mol} / \mathrm{l}) \mathrm{pH} 7.4$ & Glass \& PVC & $<5$ \\
\hline Neutral pork & benzyl alcohol $1.0 \mathrm{~g} / 100 \mathrm{ml} \mathrm{pH} 7.4$ & Glass \& PVC & $60-80^{\mathrm{a}}$ \\
\hline Neutral pork & benzyl alcohol $1.0 \mathrm{~g} / 100 \mathrm{ml}, 0.05 \%$ SDS & PVC & $60-80^{\mathrm{a}}$ \\
\hline Sulphated beef & glycerol $1.27 \mathrm{~g} / 100 \mathrm{ml}$ & Glass & $14^{\mathrm{a}}$ \\
\hline Sulphated beef & EDTA $(1 \mathrm{mmol} / \mathrm{l})$ & Glass & $22^{\mathrm{a}}$ \\
\hline Sulphated beef & polyethylene glycol $1 \mathrm{~g} / 100 \mathrm{mI}$ & Glass & 5 \\
\hline Sulphated beef & sodium deoxycholate $1 \mathrm{~g} / 100 \mathrm{ml}$ & Glass & $<3$ \\
\hline Neutral pork & glycerol $1.27 \mathrm{~g} / 100 \mathrm{ml}$ & Glass & $<3$ \\
\hline Neutral pork & EDTA $(1 \mathrm{mmol} / \mathrm{l})$ & Glass & $<3$ \\
\hline Neutral pork & polyethylene glycol $1 \mathrm{~g} / 100 \mathrm{ml}$ & Glass & $<3$ \\
\hline Neutral pork & sodium deoxycholate $1 \mathrm{~g} / 100 \mathrm{ml}$ & Glass & $<3$ \\
\hline \multirow[t]{2}{*}{ Neutral pork } & Tris $(10 \mathrm{mmol} / \mathrm{l})$ in & & \\
\hline & Benzyl alcohol $1 \mathrm{~g} / 100 \mathrm{ml}$ & Glass & $<5$ \\
\hline \multirow[t]{2}{*}{ Neutral pork } & Tris $(100 \mathrm{mmol} / \mathrm{l})$ with & & \\
\hline & polyethylene glycol $10 \mathrm{~g} / \mathrm{l}$ & Glass & $<5$ \\
\hline \multirow[t]{2}{*}{ Neutral pork } & histidine $(100 \mathrm{mmol} / \mathrm{l})$ with & & \\
\hline & benzyl alcohol $10 \mathrm{~g} / 1$ & Glass & $<5$ \\
\hline \multirow{2}{*}{ Neutral pork } & histidine $(10 \mathrm{mmol} / \mathrm{l})$ with & & \\
\hline & polyethylene glycol $10 \mathrm{~g} / 1$ & Glass & $<5$ \\
\hline \multirow[t]{2}{*}{ Neutral pork } & histidine $(10 \mathrm{mmol} / \mathrm{l})$ with & & \\
\hline & sodium caprylate $(10 \mathrm{mmol} / \mathrm{l})$ & Glass & $<5$ \\
\hline Neutral pork & acetyl tryptophan $(10 \mathrm{mmol} / \mathrm{l})$ & Glass & $<5$ \\
\hline Neutral pork & $\begin{array}{l}\text { albumin } 50 \mathrm{~g} / 1 \text {, sodium caprylate } 40 \mathrm{~mol} / \mathrm{l} \text { and } \\
\text { acetyl tryptophan } 40 \mathrm{~mol} / 1\end{array}$ & Glass & $<5$ \\
\hline Neutral pork & $\begin{array}{l}\text { BES (N,N-bis, } \\
\text { 2-hydroxy-ethyl-2-aminoethane } \\
\text { sulphonic acid })(10 \mathrm{mmol} / 1)\end{array}$ & Glass & $<5$ \\
\hline \multirow[t]{2}{*}{ Neutral pork } & $\begin{array}{l}\text { HEPES (N-2-hydroxy- } \\
\text { ethylpiperazine-N-2- }\end{array}$ & & \\
\hline & ethane sulphonic acid) $(10 \mathrm{mmol} / \mathrm{l})$ & Glass & $<5$ \\
\hline \multirow[t]{2}{*}{ Neutral pork } & $\begin{array}{l}\text { TES (N-tris-(hydroxymethyl) } \\
\text {-methyl-2-aminoethane }\end{array}$ & & \\
\hline & sulphonic acid) $(10 \mathrm{mmol} / \mathrm{l})$ & Glass & $<5$ \\
\hline $\begin{array}{l}\text { Neutral pork } \\
(2 \mathrm{U} / \mathrm{ml})\end{array}$ & sodium phosphate $(0.02 \mathrm{~mol} / \mathrm{l})$ & PVC & $8-11$ \\
\hline$(2 \mathrm{U} / \mathrm{ml})$ & histidine $(0.01 \mathrm{~mol} / \mathrm{l})$ & PVC & $8-11$ \\
\hline$(2 \mathrm{U} / \mathrm{ml})$ & dimethyl glutarate $(0.05 \mathrm{~mol} / \mathrm{l})$ & PVC & $8-11$ \\
\hline$(2 \mathrm{U} / \mathrm{ml})$ & glycylglycine $(0.01 \mathrm{~mol} / 1)$ & PVC & $8-11$ \\
\hline \multirow[t]{2}{*}{$(2 \mathrm{U} / \mathrm{ml})$} & ammonium citrate $(0.01 \mathrm{~mol} / \mathrm{l})$ in & & \\
\hline & $\mathrm{NaCl}(0.154 \mathrm{~mol} / \mathrm{l})$ & PVC & 4 \\
\hline$(2 \mathrm{U} / \mathrm{ml})$ & glycine $(22.5 \mathrm{~g} / \mathrm{l})$ with $\mathrm{NaCl}(0.154 \mathrm{~mol} / \mathrm{l})$ & PVC & 4 \\
\hline
\end{tabular}

a In these solutions, the time of aggregation was difficult to interpret as small particulate matter was detectable before gross precipitation occurred

${ }^{b}$ Unless otherwise specified

For comparison, it should be noted that in our experiments using a similar rotating apparatus but at lower concentrations $(5 \mathrm{U} / \mathrm{ml})$ as required by our pumping systems, neutral pork insulin became cloudy in less than $4 \mathrm{~d}$ in $0.154 \mathrm{~mol} / 1 \mathrm{NaCl}$ and in less than $20 \mathrm{~d}$ in $1 \mathrm{~g} / 100 \mathrm{ml}$ benzyl alcohol. Other formulations are currently being investigated in this manner.

\section{Analysis of Aggregated Material}

The precipitated material produced by shaking neutral pork insulin $(5 \mathrm{U} / \mathrm{ml})$ in $0.154 \mathrm{~mol} / 1 \mathrm{NaCl}$ in both PVC and glass containers was submitted to electrophoretic analysis in an attempt to characterize the type of inter-molecular bonding which causes the for- 
Table 3

\begin{tabular}{lc}
\hline Solution & $\begin{array}{l}\text { Denaturation } \\
\text { time (h) }\end{array}$ \\
\hline Control (no additives & 20 \\
0.1965 ,5' dithio-bis-(2-nitrobenzoic acid) & 20 \\
$0.5 \%$ iodoacetic acid & 24 \\
$0.5 \%$ thiosalicylic acid & 18 \\
0.196 di-tert-butyl-p-cresol & 18 \\
$0.2 \%$ ascorbic acid & 20 \\
$0.1 \%$ EDTA & 19 \\
$0.05 \%$ nordihydroguajaretic acid & 27 \\
$0.5 \%$ B, B'-thiobis propionic acid & 20 \\
In the following 0.1\% methyl-4-hydroxybenzoate was also present \\
Control (no additives) & 20 \\
$3.5 \mathrm{M}$ urea & 10 \\
$3.5 \mathrm{M}$ guanidine & 12 \\
$7 \%$ pyridine & 7 \\
\% Triton WR 1339 & 18 \\
$28 \mu \mathrm{g} / \mathrm{ml}$ Zn & 5 days \\
\hline
\end{tabular}

mation of these aggregates. The precipitate was collected by centrifugation, dialyzed to remove salt and lyophilized prior to dissolution in the respective electrophoresis buffers.

Electrophoresis of the samples in urea $(8 \mathrm{~mol} / \mathrm{l})$ and acetic acid $(0.9 \mathrm{~mol} / \mathrm{l})$ at $\mathrm{pH} 3.0$ indicated the presence of very high molecular weight material which did not enter the gel, several high molecular weight insulin-derived materials which entered the gel, insulin itself, and some desamido insulins.

Non-reducing SDS electrophoresis at $\mathrm{pH} 8.3$ was performed using a modification of the method reported by Laemmli [40]. A certain amount of the sample did not enter the gel and a clear band of high molecular weight material was seen in addition to the insulin band. Layer gel electrophoresis in urea $(6$ $\mathrm{mol} / \mathrm{l})$ at $\mathrm{pH} 9.0$ also indicated the presence of high molecular weight or insoluble components which did not enter the gel.

All of these results point to the irreversible formation of intermolecular covalent linkages. Further analysis should indicate the nature of the groups involved in these covalent reactions.

\section{$\mathrm{CO}_{2}$ Diffusion and $\mathrm{pH}$}

$\mathrm{CO}_{2}$ diffusion through semi-permeable plastic and rubber components in insulin infusion systems can lead under certain circumstances to significant reduction in $\mathrm{pH}$ of neutral insulin solutions. Naturally as the isoelectric point is approached precipitation of the protein occurs. At present, work is being conducted to elucidate buffering systems that are compatible with the hormone. To date all solutions prepared with sodium phosphate buffer have led to precipitation of zinc phosphate from the solution. In lieu of the above, two of our most recent implants in beagles employed insulin solutions containing no buffering system. Flow was maintained in the implants for 6-9 weeks at which time flow terminated due to insulin plugs formed in the $61 \mu \mathrm{m}$ ID teflon flow restrictor which leads into the $0.4 \mathrm{~mm}$ ID silastic delivery catheter. The pumps were implanted subcutaneously and intravenous delivery was through the circumflex iliac vein.

Three days following total occlusion the pumps were explanted and the silastic catheters found to be occluded along their entire length with viscous white flocules. The $\mathrm{pH}$ of the viscous material was 5.8 while that of the reservoir was 7.0. As noted previously the catheters quickly became patent after standing on the bench at room temperature. It was suggested that the low flow rates $(0-0.2 \mathrm{ml} / \mathrm{d})$ just prior to explantation in combination with the elevated intravascular $\mathrm{pCO}_{2}$ levels allowed a fall in $\mathrm{pH}$ sufficient to initiate precipitation. In vitro experiments verified the above and substantiated that flow rates and catheter wall thickness must be such that the $\mathrm{CO}_{2}$ diffusion cannot lead to precipitation. Plastic or rubber insulin reservoirs should also be designed with these thoughts in mind. Of course with compatible buffers this restriction would not be necessary.

\section{Conclusions}

Abrupt changes in flow path, motion, elevated temperatures, metal ion contamination, impure insulin formulations, $\mathrm{CO}_{2}$ diffusion, $\mathrm{pH}$ drop, dissimilar metal pump components, salt concentration, inappropriate diluents, elevated temperatures, refrigeration temperatures, processing, insulin heterogeneity, and buffering systems have been implicated to a greater or lesser extent in the plugging of insulin delivery devices. Before the rate at which insulin loses its biological activity in delivery systems can be assessed it is obvious that anti-aggregating diluents must be developed and subjected to long-term testing both in vitro and in vivo. Until such stable homogenous formulations are available the knowledge presented in this article will serve to decrease, but not eliminate, the problem of insulin aggregation in delivery systems. Further experiments are in progress and preliminary results [41] provide evidence that the problems cited are not without resolution. In this regard serum apparently contains factor(s) that promote the dissolution of insulin and prevent the formation of peptide aggregates in dilute solutions [41]. Many laboratories are now working to resolve the problem of insulin aggregation in artificial delivery devices.

Acknowledgements. This work was conducted as a research project in the Artificial Pancreas Program at the Hospital for Sick Children and at Connaught Laboratories, Ltd., Toronto, Ontario. It was funded in part by Contract No. NO1-AM-9-2201 from the 
National Institutes of Health, Bethesda, Maryland and in part by grants from the Medical Research Council of Canada, and the Metal Bellows Company of Sharon, Mass.

The authors gratefully acknowledge the assistance provided by Dr. L. F. Ellis of Eli Lilly and Co., Indianapolis, Indiana; Mrs. I. Leitis, Mr. B. Wilson and Mr. M. Teitelman of the Dept. of Pathology, Hospital for Sick Children, Toronto; Mr. J. C. Van Loon, Dept. of Geology, University of Toronto, Toronto; Mr. E. Tucker and Mr. F. Prosl of the Metal Bellows Co., Sharon, Mass.; and Dr. A. Bahoric, Hospital for Sick Children, Toronto, Canada. The preparation of this review followed a suggestion to this effect made to one of its authors (AMA) by Dr. J. S. Soeldner of the Joslin Research Laboratories, during the deliberations of the Bioengineering Support Systems Workgroup of the National Conference on Diabetes: Current Status and Future Directions held in Reston, Virginia in October, 1979.

\section{References}

1. Jackman WS, Lougheed W, Marliss EB, Zinman B, Albisser AM (1980) For insulin infusion: A miniature precision peristaltic pump and silicone rubber reservoir. Diabetes Care 3: 322-331

2. Goriya Y, Bahoric A, Marliss EB, Zinman B, Albisser AM (1979) Glycaemic regulation using a preprogrammed insulin delivery device. III. Long-term studies on diabetic dogs. Diabetes 28: $558-564$

3. Irsigler K, Kritz H (1979) Long term continuous intravenous insulin therapy with a portable insulin dosage-regulating apparatus. Diabetes 28: 196-203

4. Jeffrey PD, Milthorpe BK, Nichol LW (1976) Polymerization pattern of insulin at $\mathrm{pH} 7.0$. Biochemistry 15: 4660-4665

5. Jeffrey PD (1974) Polymerization behaviour of bovine zincinsulin at neutral $\mathrm{pH}$. Molecular weight of the subunit and the effect of glucose. Biochemistry 13: 4441-4447

6. Pickup JC, Keen H, Parsons JA, Alberti KGMM (1978) Continuous subcutaneous insulin infusion: An approach to achieving normoglycemia. Br Med J 1: 204-207

7. Pickup JC, White MC, Keen H, Parsons JA, Alberti KGMM (1979) Long-term continuous subcutaneous insulin infusion in diabetics at home. Lancet II: 870-874

8. Blundell TL, Dodson GG, Dodson EJ, Hodgkin DC, Vijayan M (1971) X-ray analysis and the structure of insulin. Recent Prog Horm Res 27: 140

9. Cunningham LW, Fisher RL, Vestling CS (1955) A study of the binding of zinc and cobalt by insulin. J Am Chem Soc 77: 5703-5707

10. Fredericq E (1954) La cour de la titration de l'insulin et de ses tractions. J Polymer Sci 12: 287-300

11. Gutfreund H (1952) Reversible disassociation of insulin and its molecular weight. Biochem $\mathrm{J}$ 50: 564-569

12. Goldman J (1971) Ph. D. thesis, Univ. of Calif., Berkeley

13. Grant PT, Coombs TL, Frank BH (1972) Differences in the nature of the interaction of insulin and proinsulin with zinc. Biochem J 126: 433-440

14. Hodgkin DC (1974) Varieties of insulin. Proc Soc Endocrinol 3P-13P

15. Laskowski MJr, Widom JM, McFadden ML, Scheraga HA (1956) Differential ultraviolet spectra of insulin. Biochim Biophys Acta 19: 581-582

16. Oncley JL, Ellenbogen E, Gitlen D, Gurd FRN (1952) Protein interactions. J Physiol Chem 56: 85-92

17. Paselk RA, Levy D (1974) Fluorine nuclear magnetic resonance studies of triflouracetyl-insulin derivatives. Effects of $\mathrm{pH}$ on conformation and aggregation. Biochemistry 13: 3340-3345

18. Pekar AH, Frank BH (1972) Conformation of proinsulin. A comparison of insulin and proinsulin self-association at neutral pH. Biochemistry 11: 4013-4016
19. Praissman M, Rupley JA (1968) Comparison of protein structure in the crystal and in solution. II. Tritium-hydrogen exchange of zinc-free and zinc insulin. $J$ Biochem 7 : 2431-2445

20. Steiner RM (1952) Reversible association processes of globular proteins. I. Insulin. Arch Biochem Biophys 39: 333-354

21. Waugh D (1954) Protein-protein interactions. Adv Protein Chem 9: 325-437

22. Holladay LA, Ascoli M, Puett D (1977) Conformational stability and self-association of zinc-free bovine insulin at neutral pH. Biochim Biophys Acta 494: 245-254

23. Thurow H (1979) Studies on the denaturation of dissolved insulin. 2nd International Insulin Symposium, Aachen

24. Wu Gay-May (1974) Purification, stability and physico-chemical behaviour of bovine insulin. Dissertation Abstracts Vol. 35 , no. 75-7816

25. Jackson PL, Storvick CS, Hollinden CS, Stroeth L, Still ZJG (1971) Neutral regular insulin (Abstracts). Diabetes 20 (Suppl 1): 361

26. Mirsky IA, Kawamura K (1966) Heterogeneity of crystalline insulin. Endocrinology 78: 1115-1119

27. Steiner DF, Terris S, Chan SJ, Rubenstein AH (1976) Chemical and biological aspects of insulin and proinsulin. pp. 53-92. In: Luft R (ed) Insulin. A. Lindgren, Molndal, Sweden

28. Dillon WW, Romans RG (1967) Heterogeneity of insulin. II. Chromotography of insulin on carboxymethyl cellulose in urea containing buffers. Can J Biochem 45: 221-237

29. Schlichtkrull J (1979) Insulin in perspective. IDF Bull 24: $7-10$

30. Yue DK, Turtle JY (1975) Antigenicity of "Monocomponent" pork insulin in diabetic subjects. Diabetes 24: 625-632

31. Schlichtkrull J (1977) Purity and antigenicity of insulin preparations. Acta Paediatr Scand [Suppl] 270: 37-40

32. Mahbouba M, Smith HJ (1977) Thiolation and disulphide cross-linking of insulin to form macromolecules of potential therapeutic value. Adv Exp Med Biol 86A: 247-259

33. Massey DE, Smyth DG (1972) The effect of acylation on the molecular size of insulin. Eur J Biochem 31: 470-473

34. Maloney PJ, Aprile MA, Wilson S (1964) Sulphated insulin for treatment of insulin resistant diabetics. J New Drugs 4: $258-263$

35. Stephenson NR, Romans RG (1960) Thermal stability of insulin made from zinc insulin crystals. J Pharm Pharmacol XII: 372-376

36. Pingel M, Vølund A (1972) Stability of insulin preparations. Diabetes 21: 805-813

37. Nolan C, Margoliash E, Peterson JD, Steiner DF (1971) The structure of bovine insulin. J Biol Chem 246: 2780-2787

38. Thurow H (1979) The stability of highly concentrated neutral insulin solutions. IDF Abstr.; Workshop on artificial beta cell in diabetes research and management. Proceedings, $\mathrm{p} 13$

39. Lougheed W, Albisser AM (1980) Insulin delivery and the artificial beta cell: Luminal obstructions in capillary conduits. Int $\mathbf{J}$ Artificial Org 3: 50-56

40. Laemmli UK (1970) Cleavage of structural proteins during the assembly of the head of bacteriophage T4. Nature 227: 680-685

41. Albisser AM, Lougheed W, Perlman K, Bahoric A (1980) Non-aggregating insulin solutions for long-term glucose control in experimental and human diabetes. Diabetes 29: $241-243$

Dr. A. M. Albisser

Biomedical Research

The Hospital for Sick Children

555 University Avenue

Toronto M5G IX8

Canada 